Article

\title{
Investigating e-Retailers' Intentions to Adopt Cryptocurrency Considering the Mediation of Technostress and Technology Involvement
}

\author{
Runhan Wu ${ }^{1}$, Kamran Ishfaq ${ }^{2}$, Siraj Hussain ${ }^{2, *}$, Fahad Asmi ${ }^{3, *(\mathbb{D}, \text { Ahmad Nabeel Siddiquei }}{ }^{4}$ (D) \\ and Muhammad Azfar Anwar ${ }^{5}$
}

check for updates

Citation: Wu, R.; Ishfaq, K.; Hussain, S.; Asmi, F.; Siddiquei, A.N.; Anwar, M.A. Investigating e-Retailers' Intentions to Adopt Cryptocurrency Considering the Mediation of Technostress and Technology Involvement. Sustainability 2022, 14, 641. https://doi.org/10.3390/ su14020641

Academic Editor: Xuesong Zhai

Received: 18 October 2021

Accepted: 24 November 2021

Published: 7 January 2022

Publisher's Note: MDPI stays neutral with regard to jurisdictional claims in published maps and institutional affiliations.

Copyright: (c) 2022 by the authors. Licensee MDPI, Basel, Switzerland. This article is an open access article distributed under the terms and conditions of the Creative Commons Attribution (CC BY) license (https:// creativecommons.org/licenses/by/ $4.0 /)$.
1 School of Business, East China University of Science and Technology, Shanghai 200237, China; runhanwu@mail.ecust.edu.cn

2 Department of Sociology, Bahauddin Zakariya University, Multan 60800, Pakistan; dr.kamran@bzu.edu.pk

3 Department of Science and Technology of Communication, University of Science and Technology of China, Hefei 230026, China

4 Bond Business School, Bond University, Gold Coast 4226, Australia; asiddiqu@bond.edu.au

5 Research Institute of Business Analytics and Supply Chain Management, College of Management, Shenzhen University, Shenzhen 518060, China; azfar@szu.edu.cn

* Correspondence: siraj.raza@bzu.edu.pk (S.H.); fasmie@ustc.edu.cn (F.A.)

\begin{abstract}
Cryptocurrencies have transgressed ever-changing economic trends in the global economy, owing to their conveyance, security, trust, and the ability to make transactions without the aid of formal institutions and governing bodies. However, the adoption of cryptocurrency remains low among stakeholders, including e-retailers. Thus, the current work explores the intentions of e-retailers in the Asia and Pacific region to adopt cryptocurrencies. This study considers the TAMbased SOR, with a combination of non-cognitive attributes (compatibility and convenience) proposed as stimuli for e-retailers to adopt the examined cryptocurrencies. The findings indicate that the proposed non-cognitive attributes are critical in determining e-retailers' technostress (emotional state). Moreover, it was found that technostress among e-retailers profoundly impacts their intentions to adopt cryptocurrency in business settings. Meanwhile, regulatory support communication can be used to help regulatory bodies and governing institutions control the future economy worldwide. The proposed study offers significant theoretical and practical contributions through its investigation of eretailers' intentions to adopt cryptocurrency for the first time in the particular context of technostress and regulatory support.
\end{abstract}

Keywords: cryptocurrency; e-retailers; compatibility; regulatory support; technostress; TAM-based SOR

\section{Introduction}

Emerging financial technologies (also referred to as fintech) have abruptly transformed traditional e-commerce markets [1]. Fintech refers to the unique type of technology related to the improvement, automation, use, and delivery of financial services based on technobased convenience in the financial sector, which increases ease-of-use by providing roundthe-clock availability [2], accessibility [3], and security [4]. Fintech has assisted corporations, retailers, and consumers in carrying out their financial processes and operations efficiently, easily, transparently, and securely [5]. It is a consumer-oriented phenomenon intended to provide confidentiality and control. Moreover, cryptocurrency offers an irreversible, debt-free, and global solution. Fintech is also challenging the current best practices of the conventional financial system, as it is eliminating the role of intermediaries and third-party governance [6].

Consequently, digital currencies are becoming increasingly relevant in the financial industry. However, they still have a low adoption rate. The most significant challenges encountered by the financial industry, including consumers and retailers, are price volatility 
and inconsistent market flux [7]. Other obstacles include identity theft, credit risks, internet fraud, fraudulent cards, and insecure monitoring systems [8]. However, COVID-19 has changed the traditional market economy and made room for new trends, where fintech has attracted stakeholders who are eager to adopt techno-based solutions in commercial and non-commercial settings [9]. Recent regulatory initiatives include strict measures that are thought to be critical for the growth, success, and adoption of cryptocurrencies in China [10] and South Korea [11].

Bitcoin has ushered in a new era of rapid cryptocurrency adoption. The cryptocurrency market grew from 66 million to 100 million participants between May 2020 and February 2021 [12]. Data concerning usage in 55 countries reveals that 31\% of Nigerian citizens are crypto users. By 2020, one in every three Nigerians reported using crypto, while only $6 \%$ of Americans reported the same. The higher use of crypto in Nigeria is due to cheap transactions, instant payments through cell phones, and double-digit inflation. Substantial proportions of crypto users or investors are also reported in Vietnam (21\%), South Africa $(17.8 \%)$, the Philippines (19\%), Peru (16\%), Turkey (16\%), Colombia (15.3\%), Argentina $(14.3 \%)$, and Indonesia (13\%). Interestingly, it has been reported that Latin America reflected a double-digit population percentage of crypto users, while Greece and Switzerland are the only European countries in the top 10 global users of cryptocurrency [12].

The literature also highlights that the recent upsurge in the economic worth of the world's leading cryptocurrencies is gaining the attention of key stakeholders in commercial markets (including consumers, product or service providers, suppliers, and logisticians). Therefore, the following research questions for the current research have been proposed.

- RQ1: How can the technological characteristics of cryptocurrencies help explain eretailers' attitudes toward them?

- RQ2: How can e-retailers' attitudes define their intentions to adopt and accept cryptocurrency as a mode of payments and transactions?

- RQ3: How can regulatory force affect e-retailers' choices to adopt and accept cryptocurrency as a mode of payments and transactions?

One of the novelties of the present work is that we bifurcated attitudes toward cryptocurrency into uncertainty-based technostress and e-retailers' involvement. Technostress and involvement were examined to underline the dynamics of these two distinctive attitudes while shaping e-retailers' intentions to adopt cryptocurrencies in business settings. Moreover, recent changes in cryptocurrency policies in the countries with the most cryptocurrency users in Asia and the Pacific region are critical to defining and outlining the future of cryptocurrencies in this region.

This study accomplishes the objective of framing the behavioral modeling of e-retailers. Moreover, it contributes to the academic sphere through its novelty of using regulatory support and technostress to examine e-retailers' intentions to adopt cryptocurrency.

\section{Literature}

\subsection{Empirical Background}

Cryptocurrency is an emerging, technologically-mediated payment method that facilitates exchange value between buyers and sellers without exposing their identities and while bypassing the need for third-party channels, such as financial institutions [13]. Cryptocurrency is a depiction of digital value that is independently created without the interference of any central bank or authority. This unique payment method provides consumers and retailers with a broad spectrum of exchanges while neglecting traditional payment service providers and their regulations [14]. By contrast, cryptocurrency-based payment methods are based on peer-to-peer networks that are maintained by computer nodes equipped with the power to operate the network and software [15].

Cryptocurrency has uncovered new transaction mechanisms that have benefited stakeholders, retailers, and consumers. The irreversible function of cryptocurrencies increases trust, security, and popularity in the aforementioned context. Transactions are completed within a few minutes, and the users' geographic locations remain confidential [16]. 
The context of cryptocurrency buyers or customers has been studied extensively. There is an upward trend in the use of cryptocurrencies owing to the comfort and confidence associated with digital currency [7]. This lowers risk among its users and grows their wealth while they interact with socially distant and unknown service providers via this technologically developed medium [1].

Albayati emphasized that experience and regulatory support predict customers' reliance on cryptocurrency [17]. In another work, Wani and Ali [18] explored consumers' intentions to use cryptocurrency (bitcoin) and revealed that its perceived usefulness, ease of use, and risk might refine usage intentions. Conversely, the aforementioned study by Albayati et al. found that consumers do not think of bitcoin as a technology; instead, they consider it a new and secure form of money (i.e., an asset) [17].

Interestingly, during the COVID-19 pandemic, cryptocurrencies were seen as a secure payment and transaction method, as they reduced the need for physical interactions between people [19]. According to a report by the Chartered Professional Accountants of Canada, users prefer to adopt technological innovations that positively correlate with legislation and legitimacy. Furthermore, perceived risk is the most vital factor determining consumers' decisions to use bitcoin because it can increase its market cap through enhanced user conviction [20]. Cryptocurrencies have become a substantial exchange of value among consumers, as they fulfill current market needs [4].

Maria Goreti argued that cryptocurrencies are redefining the financial industry as consumers demonstrate a growing preference for digital currencies since secure facilitating conditions are currently available for the active stakeholders of the commodity (cryptocurrencies). Arias-Oliva et al. examined the factors that influence people's decisions to use bitcoin in Spain, citing facilitating conditions, effort expectancy, and performance expectancy as strong predictors [21]. Nonetheless, a minimal portion of the literature explores the current scenario where business entities or retailers are adopting cryptocurrencies to fulfill market demands by adapting to emerging trends in fintech (i.e., cryptocurrencies).

Only a few studies have investigated technologically-mediated payment adoption methods by business entities or suppliers [22]. Hove and Karimov investigated retailers' views on the risks of adopting digital payment methods in central Asia [23]. They revealed that only retailers who offer highly valued products or services accept cryptocurrencies. Moreover, Grüschow et al. analyzed the credit efficiency and cost of various payment instruments according to data collected from an immense online retailer in the fashion industry [24]. Surprisingly, a large number of sales were made through prepayment methods. However, small-value products are usually transacted through invoices.

Polasik et al. conducted a study on 108 retailers from different countries to seek the significance of bitcoin in retailers' sales [7]. Interestingly, the researchers determined that bitcoin has significant importance among small retailers and startups in developing countries, as well as those with a shadow economy. Interestingly, bitcoin is the most wellrecognized cryptocurrency by consumers, retailers, and business entities. Hung et al. [25] explored how trading activities affect price discovery within bitcoin markets. They reported that the trading activities of retailers were negatively associated with price discovery, which ultimately destabilizes the market.

Regarding the regional distribution and concentration of retailers who accept cryptocurrency, there is a large proportion of such retailers in Europe and North America. However, the largest concentrations of crypto-accepting retailers are in the Asia-Pacific region, Africa, Latin America, and the Middle East. Although few companies accept bitcoin, some of them are massive multinational companies, such as Microsoft, Dell, Wikipedia, Virgin Atlantic, and Expedia.

Many impediments limit retailers' intentions to adopt cryptocurrencies. For one, cryptocurrency lags behind traditional currencies owing to its high price volatility factor. Abrupt crashes of crypto markets have surprised crypto users and retailers. The magnitude of the fluctuation is higher than expected, creating uncertainty in the market. Similarly, people who own a notable share of bitcoins can manipulate the market, which also affects 
retailers' willingness to adopt cryptocurrency. Further empirical evidence suggests that these factors are consequences of a lack of training and that the institutional adoption of cryptocurrencies can increase its users.

Additionally, financial organizations such as Venmo and Paypal increased their consumer bases from various demographics after deciding to accept cryptocurrency. Another training-related barrier limiting the use of cryptocurrency is the new platforms used to enter crypto markets. However, this hurdle can be removed by including platforms that consumers and retailers are already using. Although some information is known, the current literature contains a gap regarding e-retailers' intentions to adopt cryptocurrencies.

\subsection{Theoretical Background}

Rogers' theory of innovation diffusion is the earliest instance of persuasive psychological modeling for technology or innovation adoption [26]. Rogers argued that innovation adoption begins with knowledge, which gives way to persuasion, decision-making, implementation, and the confirmation to accept or reject an innovation [18]. Among other prominent persuasive psychological models contributing to IS research, the theory of reasoned action, first proposed by Ajzen and Fishbein [27], is of particular value. It states the importance of two aspects - attitudes and subjective norms-while determining individuals' behavioral intentions.

Moreover, Albert Bandura's (1986) work in the field of psychology and social sciences proposed the social cognitive theory. This theory mentions that cognitive competence directs one's behavioral intention to use a technology [28]. Davis (1989) extended the theory of technology acceptance model in developing the theory of reasoned action. Moreover, the technology acceptance model (TAM) asserts that perceived usefulness and perceived ease of use can determine a person's intention to use technology.

Ajzen's (1991) theory of planned behavior is one of the best-known technologyadoption models. Ajzen argued that attitudes, subjective norms, and perceived control influence the behavioral intentions of an individual. Taylor and Todd (1995) combined the TPB and the TAM into what is known as the decomposed theory of planned behavior.

Apart from the theoretical models mentioned above, the contribution of UTAUT [29] and UTAUT2 [30] are prominent. Several research initiatives have employed biometrics to understand behavioral intentions [31,32]. However, in the recent cryptocurrency adoption literature, the TPB $[33,34]$ and TAM $[17,35]$ have emerged as the most persuasive psychological models. Therefore, the authors of the present work adopted the TAM to address the research questions (stated in Section 1).

To enhance the theoretical novelty of the current research, the authors proposed a TAM-based stimulus-organism-response (SOR), a neo-behavioristic theoretical framework initially formulated by Mehrabian and Russell (1974). According to SOR, individual responses usually trigger sensory factors in the environment. These specific responses, in turn, could persuade the individual to avoid or accept a particular domain [36,37]. SOR also explains how external environmental cues might affect internal cognitive states, which helps define individual behavioral responses [38,39].

Mehrabian and Russell (1974) affirmed that the stimuli conceptualized the role of sensory variables in a particular milieu of the SOR framework. The $O$ (organism) in SOR refers to the sentimental responses to external or environmental stimuli (Fu et al., 2020). It can be divided into three different states: (1) the extent of gratification (pleasure-displeasure), (2) the degree of mental activeness (arousal-non arousal), and (3) the sentiments of control on the actions (dominance-submissiveness) [40]. Notably, the SOR framework has a wide range of applications in academic research while underlining the behavioral mapping in the case of information system research [41], environmental studies [42], e-commerce [43], hospitality [44], pandemic [45], and social and behavioral studies [46].

The authors of the current research utilized TAM-based SOR as a unique theoretical model to examine e-commerce stakeholders' intentions to adopt cryptocurrency as a payment/transaction method in their business model(s). TAM-based SOR is a novelty of the 
current study intended to help address the role of extended/external attributes, which have previously been highlighted as a critical limitation of TAM [47]. Moreover, several studies were employed to embed, extend, and adapt the TAM with additional factors to maximize the variance explained while mapping retailers' intentions to adopt or avoid technology and innovations.

Considering the relationship between the empirical and theoretical backgrounds, the rationale underlying the current study is that there is an urgent need to map this particular phenomenon through behavioral modeling because there is a scarcity of studies that have used the TPB. However, in the present study, behavioral modeling has been executed through TAM-based SOR to explain e-retailers' behavioral intentions. The constructs proposed within the proposed TAM-based SOR framework will be discussed in the following section.

\section{Hypotheses Development}

\subsection{Stimuli}

A stimulus is any event or object that triggers a sensory or behavioral response in an organism. This effect is due to the internal evaluation of the stimuli in the organism, which may be conscious or unconscious. The particular stimuli of concern in the present study are TAM-based factors, namely perceived compatibility, efficacy, and technological characteristic (functional transparency). The research underlined these triggers across the spectrum of TAM-based perceived ease of use and usefulness. There has been a wide range of research on people's intentions to adopt cryptocurrency [48]. The current work contributes to the literature on this phenomenon by shedding light on TAM-based SOR.

Cryptocurrencies' compatibility with businesses is related to individuals' perception and understanding of their potential value and benefits. This compatibility can be achieved by incorporating cryptocurrency-based transaction or payment methods within the existing e-commerce environment. The compatibility of the innovation (i.e., cryptocurrency) is also subject to the adopter's needs, goals, and previous experiences [49]. Therefore, compatibility with a business increases an individual's intentions to adopt cryptocurrency [50].

Plouffe et al. [51] stated that compatibility is a vital factor affecting retailers' intentions to adopt digital innovations. Meanwhile, Wood et al. (2018) studied the adoption of bitcoin among 121 consumers and indicated that relative benefits, visibility, and compatibility significantly affected bitcoin adoption. Moreover, Ayedh et al. [52] studied 200 Malaysians and highlighted that the compatibility, awareness, and facilitating conditions may determine the effect of interest in bitcoin.

In the present study, the researchers have adopted the definition used in a related study [53], which stated that compatibility is a "perceptual construct that is fit between the IT and the work that triggers the employees to use the system." In the specific context of bitcoin, perceived compatibility researchers have claimed that compatibility is the fit between the cryptocurrency and the user's perceptions about adopting it. From the above discussion, the following hypothesis was put forth.

Hypothesis 1 (H1(a and b)): Perceived cryptocurrency compatibility with a business significantly affects a retailers' perceived technostress and degree of involvement with the technology.

Perceived cryptocurrency functional transparency refers to how firmly users believe that the flow and processes associated with cryptocurrency are understandable and communicable. Functional transparency has been maintained in digital currencies through a clear peer-to-peer architecture in which privacy and security concerns are addressed by reliable encryption mechanisms [54]. Fundamentally, blockchain-based digital currencies keep the information flow more accountable and transparent, as the blockchain offers an environment for data immutability, transaction records, and irrevocable transactions [55]. Cryptocurrencies also reduce the risk of information theft and delay. 
Undoubtedly, cryptocurrency's functional transparency is vital to defining an individual's intentions to adopt it [56]. Authors have further explained the argument of Pardo et al. [57] that transparency is an inventible part of the future of global trading practices. Thus, the following hypothesis has been proposed.

Hypothesis 2 (H2(a and b)): Perceived cryptocurrency functional transparency significantly affects retailers' perceived technostress and degree of involvement with the technology.

Perceived cryptocurrency efficacy is an individual's self-belief to transact, receive, share, or maintain the digital currency wallet. It can be thought of as a specialized view from the confidence of the individual to work in a blockchain-based environment [56]. In the context of the proposed spectrum of stimuli related to SOR, perceived cryptocurrency efficacy reflects the TAM-based perceived ease of use. Intentions to adopt the technology are primarily based on the utility, quality, and efficacy of the individuals. Thus, the new, easy avenues created by blockchain are increasing individuals' tendencies to adopt cryptocurrencies [58]. The elimination of the reliance on third-party service providers and reduced overhead transaction costs may further increase people's intentions to use cryptocurrencies [59]. Based on the above discussion, the following hypothesis was proposed.

Hypothesis 3 (H3(a and b)): Perceived cryptocurrency efficacy significantly affects retailers' perceived technostress and their degree of involvement in the technology.

\subsection{Organism and Response}

Criag [60] introduced the term "technostress," which refers to the cognitive state by which an individual fails to deal with technology healthily. It is also known as technoanxiety [61], technophobia [62], and digital depression [63]. Technostress can be caused by a high workload [64], a low degree of efficacy [65], the ability to counter the technology [66], perpetual urgency [67], and high expectations to work faster [68]. Li and Wang [69] have argued that technostress negatively impacts individual commitment, performance, and productivity. The literature also states that individual self-efficacy is strongly associated with perceived ease of use and techno-anxiety [70]. In the context of IS research, technostress and its relationships with perceived ease of use and perceived usefulness have been researched intensively [70]. Technostress has been adopted per the stance of a related study [71], which defined technostress as the "stress that user experience as a result of their use of information systems in the organizational context." Meanwhile, the present researchers have operationalized this as the failure to handle the information needed to counter cryptocurrency's technology. Hence, the following hypothesis has been proposed.

Hypothesis 4 (H4): Perceived technostress (driven by techno-uncertainty) strongly influences retailers' intentions to adopt cryptocurrency in a business setting.

Roger [72] stated that attitude is a critical element influencing technology adoption. Atabek [70] studied 51 university students and remarked that a positive attitude towards computers significantly determines the intention to accept an e-learning environment. Altawallbeh et al. [73] found that positive attitudes directly influence technology adoption. Similarly, developing countries' lack of IT experience can hinder technology adoption [50]. Interestingly, individuals accept technological changes when they align with their practices and opinions [49]. Blockchain-based innovation serves as the basis of the technological attribute of transparency [74]. Moreover, the degree of adoption is associated with an individuals' self-efficacy [75] and perceived ease of use [76]. Hence, the following hypothesis has been proposed.

Hypothesis 5 (H5): Perceived technology involvement strongly influences retailers' intentions to adopt cryptocurrency in a business setting. 


\subsection{Moderating Role of the Regulatory Environment}

The term 'regulatory environment' refers to the legal frameworks that are typically developed by governments or institutions to ensure that all obligations are met and that any violations by the consumers or service providers of technologies are avoided [17]. It significantly facilitates business and technological deployment monitoring in various regions while maintaining the interest of all stakeholders [77]. Legislation ensures the smooth operation of technologies under certain conditions [17]. In the context of cryptocurrencies, regulatory support is mandatory to avoid uncertainties. Also, strong governmental regulations and support can foster consumer trust in technology [78]. Nonetheless, the evolution of cryptocurrencies has encountered several problems regarding the absence or inconsistency of the laws and weak regimes [17].

Efforts to regulate the legality of cryptocurrency will remain ineffective until digital rights, contracts, and money attain an appropriate place in the realm of civil rights. Consequently, the Australian Taxation Office (ATO) has proclaimed that digital currency is a commodity, as opposed to a currency; thus, it is not subject to the tax regulations defined by the authorities in different countries, such as Singapore and Canada. Bitcoin transactions are akin to a barter system, including in terms of tax regulations [79].

In recent years, several governing bodies worldwide have formulated comprehensive regulatory reforms to address cryptocurrencies and related challenges regarding governance; a few examples are listed in Table 1.

Table 1. Noticeable regulatory reforms in various countries.

\begin{tabular}{|c|c|c|}
\hline Region & $\begin{array}{c}\text { Reform Reporting } \\
\text { Date }\end{array}$ & Effect on \\
\hline $\begin{array}{c}\text { United States-Internal Revenue } \\
\text { Service (IRS) }\end{array}$ & February 2020 & $\begin{array}{l}\text { Customers, businesses, } \\
\text { governments }\end{array}$ \\
\hline $\begin{array}{c}\text { Canada-Bitcoin exchange-traded } \\
\text { fund (ETF) }\end{array}$ & February 2021 & $\begin{array}{l}\text { Investment industry, money } \\
\text { services firms }\end{array}$ \\
\hline $\begin{array}{l}\text { United Kingdom-Financial Conduct } \\
\text { Authority (FCA) }\end{array}$ & 1 April 2013 & Taxation, governments \\
\hline Japan-Payment Services Act (PSA) & May 2021 & Governments, businesses \\
\hline $\begin{array}{l}\text { Australia-AML/CTF 2006)-Under } \\
\text { Section 5, crypto became legal }\end{array}$ & 2017 & $\begin{array}{l}\text { customers, properties, } \\
\text { taxation }\end{array}$ \\
\hline
\end{tabular}

Based on the overview of the existing evolution of the policy worldwide, the authors adopted the generalized view to accept the holistic nature of the study and encapsulate the concept of "regulatory support." The authors also emphasized the role of e-retailers" perceptions of related regulatory reforms in their lenience, friendliness, and supportive nature. Blockchain-based security protocols explicitly express that policies and laws play a crucial role in identifying the authorization and authentication of any particular entity. Thus, legal protection and institutional support are prerequisites for consumers when considering cryptocurrency in a business environment [80]. Therefore, the following hypothesis has been proposed.

Hypothesis 6 (H6(a and b)): Regulatory support moderates the relationships of technostress and techno involvement with retailers' intentions to adopt cryptocurrency in a business setting.

\section{Methods}

The following sub-sections discuss the research design. Specifically, Section 4.1 elaborates on the instruments adopted for the current research and describes the pilot test conducted to check the validity of the instrument. In Section 4.2, the criteria of sample population selection and limitation in sample representation are clearly outlined by defining the margin of error and confidence interval of the sample size, as advised by Goddon [81]. 


\subsection{Instrument Development}

The authors developed the measurement instrument utilized in the current research based on extant literature (see Table 2). All items of the instrument are answered using a five-point Likert scale ( $1=$ "strongly disagree"; $5=$ "strongly agreed"). Specifically, the threeitem instrument to measure perceived technostress (driven by techno uncertainty) was adopted from Ragu-Nathan et al. [82]. The three-item scale measuring retailers' intentions to adopt cryptocurrency was based on the work of Zhu et al. [83]. Moreover, three-item instruments were adopted from Fazal-e-hasan et al. [84] to explore cryptocurrency's compatibility with business and cryptocurrency efficacy (driving convenience). Additional three-item scales were adopted from Urban and Kujinga [85], Venkatesh et al. [86], and Dutta et al. [87] to measure the perceived regulatory support, cryptocurrency functional transparency, and technology involvement, respectively.

Table 2. Descriptive observations derived from the primary data.

\begin{tabular}{|c|c|c|c|}
\hline Demographics & Detail & Percentage & Frequency \\
\hline \multirow{4}{*}{$\begin{array}{l}\text { Representing } \\
\text { e-entity as }\end{array}$} & Executive & 34 & 16.11 \\
\hline & Non-executive & 63 & 29.86 \\
\hline & Manager & 87 & 41.23 \\
\hline & Others & 27 & 12.80 \\
\hline \multirow{4}{*}{$\begin{array}{l}\text { Experience } \\
\text { (in years) }\end{array}$} & Less than 2 years & 52 & 24.64 \\
\hline & $2-3$ years & 84 & 39.82 \\
\hline & $3-5$ years & 44 & 20.85 \\
\hline & More than 5 years & 31 & 14.69 \\
\hline \multirow{4}{*}{ E-entity (nature) } & Non-specialized & 77 & 36.49 \\
\hline & Clothing & 08 & 03.79 \\
\hline & Furniture and appliances & 46 & 21.80 \\
\hline & Hardware and other & 80 & 37.92 \\
\hline \multirow{6}{*}{$\begin{array}{c}\text { E-entity } \\
\text { (coverage area) }\end{array}$} & $\begin{array}{c}\text { East Asia (i.e., China, North Korea, South } \\
\text { Korea, and Japan }\end{array}$ & 45 & 21.33 \\
\hline & North Asia (i.e., Russia) & 03 & 01.42 \\
\hline & $\begin{array}{c}\text { South Asia (i.e., India, Bangladesh, and } \\
\text { Pakistan) }\end{array}$ & 87 & 41.23 \\
\hline & $\begin{array}{l}\text { Southeast Asia (i.e., Singapore, the } \\
\text { Philippines, and Thailand) }\end{array}$ & 49 & 23.22 \\
\hline & Oceana (i.e., Australia and New Zealand) & 27 & 12.80 \\
\hline & $\begin{array}{c}\text { Others (i.e., Melanesia, Polynesia, and } \\
\text { Micronesia region) }\end{array}$ & - & - \\
\hline
\end{tabular}

A pilot study with twenty-five volunteer respondents (university students between the age of 21 and 27 years old) was conducted to verify the instrument's reliability and validity. After revising eight items per the suggestions and observations of the pilot study participants, the authors shared the revised instrument with two experts with expertise in consumer behavior and business studies to examine the instrument's face and content validity. After four items were further revised, the final version of the instrument was attained and used for data collection.

\subsection{Data Collection}

The primary goal of this study was to examine e-commerce entities' (including entrepreneurs and SMEs) readiness to adopt cryptocurrency and offer it to end consumers as a method in Asia and the Pacific region. The authors emphasized this region because several exemplary regions (i.e., where the best practices and integration of cryptocurrency have been observed) are located in this region. Moreover, the regulations in this region are currently changing and, thus, are critical to defining the future of cryptocurrencies. The authors collected the data using Google Forms, employing convenience sampling. Specifically, 
the authors used a search engine to identify business entities who offer cryptocurrencies as a mode of payment to end users.

The immediate contact person from each e-retailer was considered the representative of that entity. The authors assured all potential respondents of their anonymity and explained the purpose of the research to them. As stated above, the authors only considered business entities from Asia and the Pacific region. Several pre-check questions were asked to obtain information about each participant's (1) usage of cryptocurrency in the business setting; (2) residing business location, which needed to be in Asia or the Pacific region; and (3) the authority level of the respondent (to ensure they were a suitable representative of the eretail business). Only those respondents who gave appropriate responses were considered eligible to participate.

In total, 211 valid responses were used for the structural model-based hypotheses test, as put forth in Section 3. Specifically, a sample population of at least 188 participants was required to account for the unknown population size while maintaining a confidence level of $90 \%$, sample proportion of $50 \%$, and margin of error of $6 \%$, as advised by [81]. The demographic profile of the respondents is presented in Table 2.

\section{Analysis}

The current section presents the data analysis. Specifically, the internal and external reliability of the data are computed, and the hypotheses (stated in Section 3) are tested using SPSS Statistics (v.26) and SPSS-AMOS (v.24). A graphical explanation of the analysis is shown below.

Figure 1 shows that kurtosis scores help examine whether any data pattern and normality arise, which signifies the presence of tailedness in the data. Also, Harman's single factor test helps examine the risk single-factor domination among a proposed set of constructs. The favorable results allow researchers to study the internal consistency (based on factor loadings, Cronbach alpha scores, complete reliability, and internal consistency). In addition to the internal reliability test, the correlation, with average variance extracted (AVE), and HTMT scores were calculated to determine the external reliability of the collected data and proposed set of constructs.

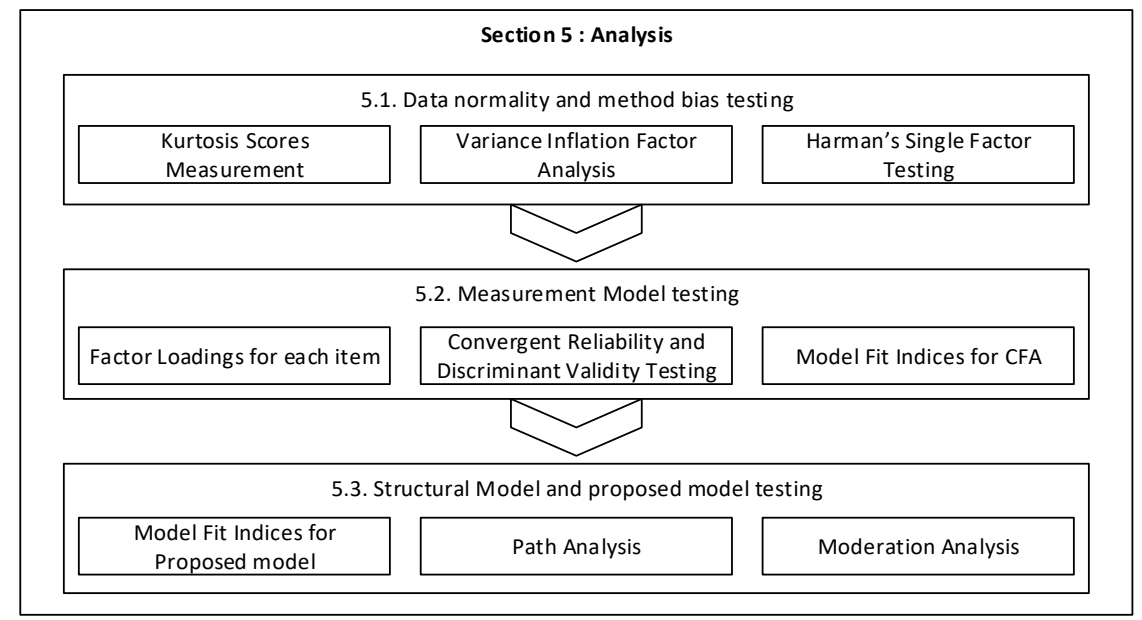

Figure 1. Graphical representation of the data analysis.

Satisfactory results were obtained from the tests for data reliability, internal and external reliability, and validity. Subsequently, the model fitness scores were computed at the level of confirmatory factor analysis (CFA) and proposed mode setting. The results indicated that only the path analysis and moderation testing could be conducted. The steps performed are described in Sections 5.1-5.3. 


\subsection{Common-Method-Bias Testing}

The authors examined the multicollinearity and normality of the collected data before conducting the model test. First, the skewness of the data was measured by computing the kurtosis score, which was below the upper cut-off limit. Second, the variance inflation score was considered as a reliability marker. The variance inflation score of each construct was within the range of 1.10-1.75, which eliminates the risk of inter-construct association among exogenous factors, as advised by Hair et al. [88].

Common method bias was also calculated as suggested by Harman's [89] single-factor method. According to Elliot and Woodward, the maximum variance extracted should be lower than 50\% [90]. The maximum variance recorded for a single factor in this study was $22.58 \%$. Thus, all values were acceptable, meaning that there was likely no risk of multicollinearity or data abnormality.

\subsection{Measurement Model Testing}

The authors performed a CFA, computing the factor loading of each item of the measurement model. The findings noted that the factor loadings for the CFA and the proposed model settings were above the lower cut-off limit suggested by Hair et al. [88]. The satisfactory factor loadings confirmed the reliability and validity of the data (Table 3).

Table 3. Factor loadings from measurements and the proposed model.

\begin{tabular}{|c|c|c|c|c|c|}
\hline $\begin{array}{l}\text { Study Measures } \\
\text { and Source }\end{array}$ & Measurement Items & Mean & SD & CFA Loadings & SEM Loading \\
\hline \multirow{3}{*}{$\begin{array}{l}\text { Technostress } \\
\text { (driven by } \\
\text { techno-uncertainty) [82] }\end{array}$} & $\begin{array}{l}\text { There are always new developments in the CC } \\
\text { as technologies that I can use in my } \\
\text { business setting. }\end{array}$ & \multirow{3}{*}{3.24} & \multirow{3}{*}{0.81} & 0.87 & 0.87 \\
\hline & $\begin{array}{l}\text { There are constant changes in the CC as } \\
\text { technologies that I can use in my } \\
\text { business setting. }\end{array}$ & & & 0.83 & 0.82 \\
\hline & $\begin{array}{l}\text { There are frequent updates/developments in } \\
\text { the CC as technologies that I can use in my } \\
\text { business setting. }\end{array}$ & & & 0.87 & 0.87 \\
\hline \multirow{3}{*}{$\begin{array}{l}\text { Intentions to adopt } \\
\text { cryptocurrency [83] }\end{array}$} & $\begin{array}{l}\text { I am willing to adopt CC in my business } \\
\text { setting as the mode of payment. }\end{array}$ & \multirow{3}{*}{3.36} & \multirow{3}{*}{1.02} & 0.96 & 0.96 \\
\hline & $\begin{array}{l}\text { I am intending to become involved in CC to } \\
\text { include it in my business setting as a mode } \\
\text { of payment. }\end{array}$ & & & 0.87 & 0.87 \\
\hline & $\begin{array}{l}\text { I will make an effort to become involved and } \\
\text { practice including CC in my business setting as } \\
\text { a mode of payment. }\end{array}$ & & & 0.77 & 0.77 \\
\hline \multirow{3}{*}{$\begin{array}{l}\text { Cryptocurrency } \\
\text { compatibility with } \\
\text { business [84] }\end{array}$} & Using CC fits my business setting & \multirow{3}{*}{3.82} & \multirow{3}{*}{0.99} & 0.83 & 0.84 \\
\hline & $\begin{array}{l}\text { Using CC fits well with the way consumers } \\
\text { shop in my e-store/e-business }\end{array}$ & & & 0.88 & 0.80 \\
\hline & $\begin{array}{l}\text { Using CC is completely compatible with my } \\
\text { e-store/e-business needs }\end{array}$ & & & 0.87 & 0.86 \\
\hline \multirow{3}{*}{$\begin{array}{l}\text { Cryptocurrency } \\
\quad \text { functional } \\
\text { transparency [86] }\end{array}$} & $\begin{array}{l}\text { I can easily understand the functionality of CC } \\
\text { as a mode for transaction purpose }\end{array}$ & \multirow{3}{*}{3.44} & \multirow{3}{*}{1.01} & 0.85 & 0.84 \\
\hline & $\begin{array}{l}\text { I was familiar with CC as a mode for } \\
\text { transaction purposes. }\end{array}$ & & & 0.80 & 0.80 \\
\hline & $\begin{array}{l}\text { I am clear about CC as a mode for } \\
\text { transaction purposes. }\end{array}$ & & & 0.79 & 0.80 \\
\hline
\end{tabular}


Table 3. Cont.

\begin{tabular}{|c|c|c|c|c|c|}
\hline $\begin{array}{l}\text { Study Measures } \\
\text { and Source }\end{array}$ & Measurement Items & Mean & SD & CFA Loadings & SEM Loading \\
\hline Regulatory support [85] & $\begin{array}{l}\text { I think the government has a friendly attitude } \\
\text { toward commercial entities that adopt CC in } \\
\text { their business settings. } \\
\text { Government has a lenient attitude toward } \\
\text { commercial entities who adopt CC in their } \\
\text { business settings. } \\
\text { Government has a supportive attitude toward } \\
\text { commercial entities who adopt CC in their } \\
\text { business settings. }\end{array}$ & 3.89 & 0.72 & $\begin{array}{l}0.79 \\
0.74\end{array}$ & $\begin{array}{l}0.83 \\
0.79\end{array}$ \\
\hline $\begin{array}{c}\text { Cryptocurrency efficacy } \\
\text { (driving } \\
\text { convenience) [84] }\end{array}$ & $\begin{array}{l}\text { Using CC will allow my business to complete } \\
\text { payment processes quickly. } \\
\text { Using CC requires little effort to complete } \\
\text { payment processes. } \\
\text { Using CC seems to be a fast way for } \\
\text { payment processes. }\end{array}$ & 3.66 & 0.78 & $\begin{array}{l}0.79 \\
0.74\end{array}$ & $\begin{array}{l}0.76 \\
0.78 \\
0.75\end{array}$ \\
\hline $\begin{array}{c}\text { Technology } \\
\text { involvement [87] }\end{array}$ & $\begin{array}{l}\text { If I heard about new technology, I would look } \\
\text { for ways to experiment with it. } \\
\text { Among my peers, I am usually the first to try } \\
\text { out new technologies. } \\
\text { I like to experiment with new technologies. }\end{array}$ & 4.24 & 0.76 & $\begin{array}{l}0.61 \\
0.76\end{array}$ & $\begin{array}{l}0.60 \\
0.73\end{array}$ \\
\hline
\end{tabular}

Abbreviations used: $\mathrm{CFA}=$ confirmatory factor analysis, $\mathrm{SEM}=$ structural equation modeling, $\mathrm{SD}=$ standard deviation.

In addition to the CFA, the model fit indices for the measurement model were noted as follows: Chi-square/degree of freedom $=2.01, \mathrm{CFI}=0.94, \mathrm{TLI}=0.93, \mathrm{IFI}=0.94$, and RMSEA $=0.06$. The population discrepancy was recorded as significant, as the RMSEA value was less than 0.08, as advised by Hu and Bentler [91]. Moreover, considering the minimum values of the discrepancy (minimum discrepancy function) (Chi-square/degree) and fit indices scores, the incremental and comparative model values were acceptable per the criteria presented by Hooper et al. [92].

The research measured the AVE and composite reliability to examine the internal and external validity of the collected data. Composite reliability helps measure the internal reliability of the items presented within each construct. It also helps to examine the shared variance of the indicators while defining the latent variable. Researchers have argued that the values of composite reliability and AVE should be equal to or greater than $0.70[93,94]$ and $0.50[94,95]$, respectively. In the present study, the AVE ranged between 0.52 and 0.73 , while the composite reliability ranged between 0.70 and 0.90 (Table 4).

Table 4. Internal and external reliability testing.

\begin{tabular}{|c|c|c|c|c|c|c|c|c|c|c|c|}
\hline & CR & AVE & MSV & $\operatorname{MaxR}(\mathrm{H})$ & TI & IAC & $\mathrm{CC}$ & $\mathrm{CF}$ & RS & $\mathrm{CE}$ & TS \\
\hline TI & 0.89 & 0.73 & 0.22 & 0.89 & 0.86 & & & & & & \\
\hline IAC & 0.90 & 0.76 & 0.32 & 0.94 & 0.34 & 0.87 & & & & & \\
\hline $\mathrm{CC}$ & 0.90 & 0.74 & 0.37 & 0.90 & 0.27 & -0.13 & 0.86 & & & & \\
\hline $\mathrm{CF}$ & 0.85 & 0.66 & 0.37 & 0.86 & 0.15 & 0.07 & 0.61 & 0.81 & & & \\
\hline RS & 0.84 & 0.64 & 0.61 & 0.85 & 0.47 & 0.54 & 0.10 & 0.16 & 0.80 & & \\
\hline CE & 0.81 & 0.59 & 0.61 & 0.81 & 0.41 & 0.57 & 0.01 & 0.18 & 0.78 & 0.77 & \\
\hline TS & 0.70 & 0.52 & 0.16 & 0.70 & -0.15 & -0.32 & 0.40 & 0.33 & -0.22 & -0.27 & 0.64 \\
\hline
\end{tabular}

Note: $\mathrm{TI}=$ technology involvement, IAC = intentions to adopt cryptocurrency, CC = cryptocurrency compatibility with business, $\mathrm{CF}=$ cryptocurrency functional transparency, $\mathrm{RS}=$ regulatory support, $\mathrm{CE}=$ cryptocurrency efficacy (driving convenience), TS = technostress (driven by techno-uncertainty). All correlation scores recorded significant at $\rho \leq 0.05$.

Furthermore, the square root of AVEs was measured and compared with the correlation scores of each construct to check the external validity of the constructs. The correlation 
scores were lower than the square root of AVEs, indicating that the data have external reliability [96].

In addition to Fornell and Larcker's [97] method, Hensler's [98] approach was adopted to measure external validity using the Hetrotrait-monotrait ratio (HTMT). The results confirmed that the data are reliable and valid (Table 5). Therefore, the authors proceeded to test the hypotheses (proposed in Section 3).

Table 5. HTMT analysis.

\begin{tabular}{cccccccc}
\hline & TI & IAC & CC & CF & RS & CE & TS \\
\hline TI & & & & & & & \\
IAC & 0.37 & & & & & & \\
CC & 0.28 & 0.12 & & & & \\
CF & 0.16 & 0.07 & 0.62 & & & \\
RS & 0.48 & 0.53 & 0.10 & 0.16 & & \\
CE & 0.42 & 0.58 & 0.02 & 0.18 & 0.79 & & \\
TS & 0.13 & 0.33 & 0.39 & 0.33 & 0.21 & 0.26 & \\
\hline
\end{tabular}

Note: TI = technology involvement, IAC = intentions to adopt cryptocurrency, CC = cryptocurrency compatibility with business, $\mathrm{CF}=$ cryptocurrency functional transparency, $\mathrm{RS}=$ regulatory support, $\mathrm{CE}=$ cryptocurrency efficacy (driving convenience), TS = technostress (driven by techno-uncertainty).

\subsection{Structural Model Testing}

According to the results, cryptocurrency efficacy (driving convenience) makes the largest contributions to technology involvement $(0.50)$ and technostress $(0.40)$ in defining retailers' intentions to adopt cryptocurrency. Accordingly, cryptocurrency compatibility with business makes contributions of 0.30 to technostress and 0.36 to technology involvement. Surprisingly, cryptocurrency functional transparency makes the lowest contributions to technostress (0.21) and technology involvement (0.15) in describing retailers' intentions to adopt the cryptocurrency. Interestingly, the mediating role of the technology involvement had a stronger relationship with technostress (0.34) than the intention to adopt cryptocurrency (0.31). The moderating role of the regulatory support makes low contributions to technostress $(0.08)$ and technology involvement $(0.02)$ when elucidating the intention to adopt cryptocurrency.

The structural path analysis shows significant fit indices. Specific model fit indices for the structural model are as follows: Chi-square/degree of freedom $=2.24, \mathrm{CFI}=0.93$, $\mathrm{TLI}=0.91, \mathrm{IFI}=0.93$, and RMSEA $=0.07$. The findings show that seven of the proposed hypotheses (H1, H3-5) were fully accepted (Figure 2). Meanwhile, H2 was partially supported, as the relationship between cryptocurrency functional transparency and technology involvement was insignificant.

The variance explained by technostress, technology involvement, and intention to adopt cryptocurrencies were $31 \%, 35 \%$, and $25 \%$, respectively. Moreover, none of the control variables employed in the current research had significant effects. Particularly, hypotheses $\mathrm{H} 1$ ( $\mathrm{a}$ and $\mathrm{b}$ ) were significant ( $\beta=0.30$ and $\beta=0.36$, respectively). The reported significant effects of potential cryptocurrency compatibility on e-retailers' perceived technostress and their involvement in cryptocurrency highlight the potential interest (acceptance) and prominent risks discussed in the extant literature [23,24,99].

The results support $\mathrm{H} 2 \mathrm{a}(\beta=0.21)$, which underlines the significant effect of cryptocurrency's functional transparency on e-retailers' technostress. The results are consistent with the findings previously reported by Asmi et al. [100]. The present study also emphasizes the strategic role of e-retailers' self-efficacy. The findings indicate that cryptocurrency efficacy is one of the strongest determinants of e-retailers' technostress (H3a: $\beta=0.40)$ and potential use of cryptocurrency ( $\mathrm{H} 3 \mathrm{~b}: \beta=0.50)$. A similar behavioral trend was reported in the literature addressing innovation adoption [101]. 


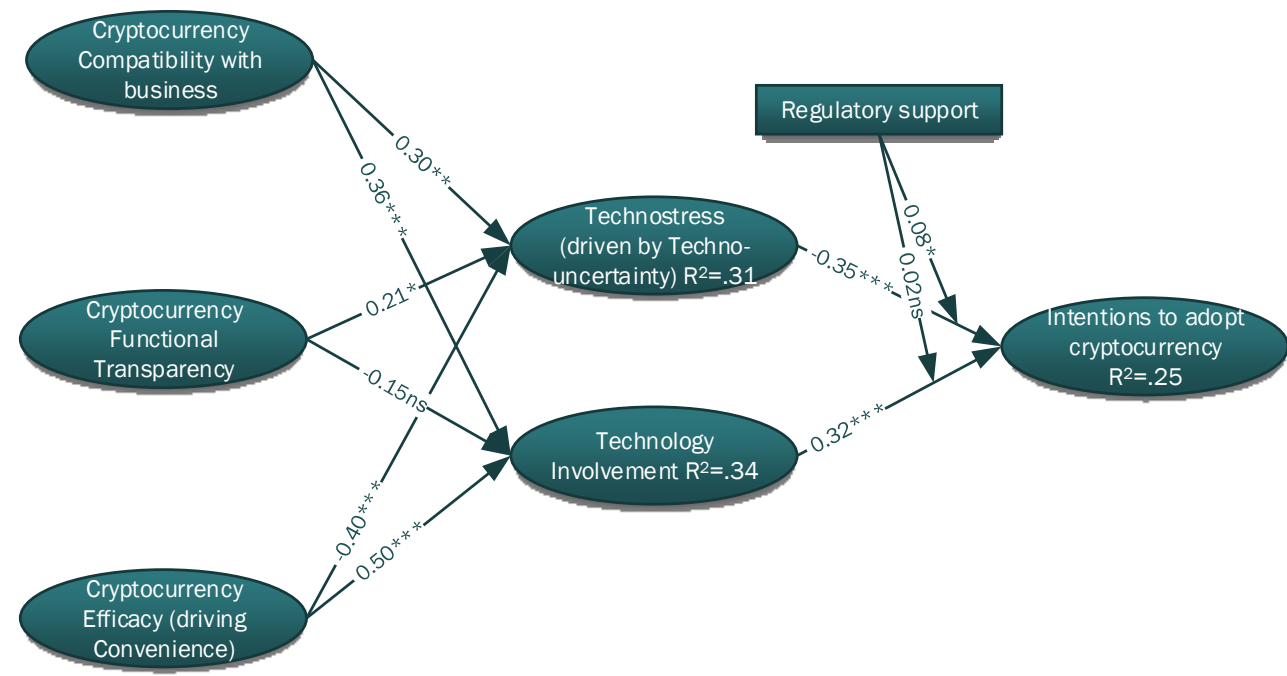

Figure 2. Path analysis for the proposed model. All correlation scores recorded significant at $\rho \leq 0.05$.

A comparison of the influences of technostress (H4) and cryptocurrency involvement $(\mathrm{H} 5)$ reveals an interesting trend, as technostress appeared to negatively influence e-retailers' intentions to adopt cryptocurrency $(\beta=-0.35)$. Similar findings were reported in a study on technology adoption behavior [102]. However, the slightly weak positive effect of technology involvement on e-retailers' intentions to adopt cryptocurrency $(\beta=0.32)$ represents a unique contribution of the present work. The findings support the results of Asmi et al. [100], who cited several potential risk factors that might harm the future of blockchain in the financial sector.

\subsection{Moderation Testing}

The moderating effect of regulatory support in the relationship between technostress and technology involvement was tested by examining the intention to adopt cryptocurrencies using hierarchal regression, as explained by Ye et al. [42]. Interestingly, the moderation effect in the relationship between technostress and the intention to adopt cryptocurrencies was significant $(\beta=0.08, \rho<0.05)$. However, the relationship between technology involvement and the intention to adopt cryptocurrencies was insignificant.

It is concluded that national monetary institutions' friendly, supportive, and lenient attitudes toward cryptocurrencies can help minimize technostress among e-retailers, who, in turn, will be more likely to adopt cryptocurrencies. However, strict measures in a few countries in Asia-namely, South Korea and China-were noticed. According to the current findings, a mixed view towards cryptocurrency adoption among e-retailers is expected in the near future.

A graphical interaction plot depicting the significant moderating relationship is shown in Figure 3. Particularly, regulatory support can reduce the negative relationship between technostress and the intention to adopt cryptocurrency. Moreover, a comparison of the effects of regulatory support in South Asian countries (i.e., Pakistan, Bangladesh, and India) revealed that regulatory support makes the greatest contribution to mitigating the negative effect of technostress. However, the slightly weak effect of regulatory support noted in East and Southeast Asian countries (due to recently imposed strict measures in prominent countries in the East and Southeast Asian region) strongly affected e-retailers' perceptions of the volatility in the price of cryptocurrency. Thus, within the East and South Asian regions, there is some disparity in retailers' opinions about regulatory support for cryptocurrency adoption. 


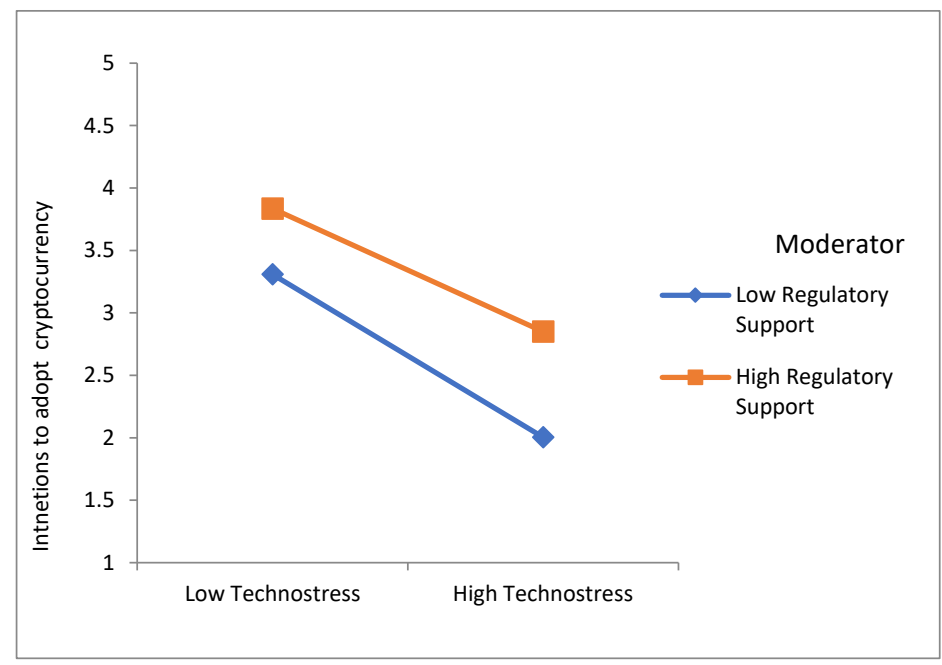

Figure 3. Interaction plot for the moderation effect of regulatory support in the relationship between technostress and retailers' intentions to adopt cryptocurrency.

\section{Discussion}

This study adopted TAM-based SOR to examine the readiness among e-retailers in the Asia-Pacific region to adopt cryptocurrencies as a payment and transaction method. Interesting findings were reported and will be discussed in relation to the research questions posed in Section 1.

Concerning the proposed exogenous factors defining technostress and technology involvement, the results show that the variance explained in the case of executives and nonexecutives is higher than in the case of managers and other respondents. According to the results, the proposed model is more explanatory regarding the executive and non-executive representatives of e-retailers (as commercial entities).

Similar findings were observed when defining intentions to adopt cryptocurrency in business settings. Specifically, the study concludes that the proposed set of exogenous factors in the case of executives and non-executive yielded 56.2\% variance. However, only $14.3 \%$ variance occurred in the case of managers and other respondents (Table 5). These findings are justified as managers and other representatives actively emphasized day-today operations, whereas executives and non-executives emphasized long-term goals and portfolio management. Thus, it can be concluded that cryptocurrencies have a strategic value in e-retail businesses, which can place commercial entities in the differentiated niche at present.

The authors also compared the variance explained among the respondents based on their experience. The variance explained by different levels of experience is reported in Table 6.

Table 6. Variance explained by endogenous factors according to a sub-group level analysis.

\begin{tabular}{lllll}
\hline \multirow{2}{*}{ Factors } & \multicolumn{4}{l}{ Variance Explained } \\
\cline { 2 - 4 } & Detail & TS & TI & IAC \\
\hline \multirow{2}{*}{ Experience } & Less than 2 years & $09 \%$ & $41.6 \%$ & $25.5 \%$ \\
& $2-3$ years & $62.8 \%$ & $30.6 \%$ & $18.2 \%$ \\
\multirow{2}{*}{ Designation } & More than 3 years & $31.1 \%$ & $33.6 \%$ & $46.9 \%$ \\
& Executives/Non-executives & $36.4 \%$ & $33.2 \%$ & $56.2 \%$ \\
\hline Abbreviations: TS $=$ technostress, TI = technology involvement, IAC = intentions to adopt cryptocurrency.
\end{tabular}

The sub-group level analysis in terms of experience highlighted that e-retailers' experience increased the psychological resilience among stakeholders in the market. In other 
words, experience encourages e-retailers to adopt cryptocurrency, as they have a good sense of trail-ability and solid risk-taking abilities.

As it concerns RQ1, the study reported the critical role of TAM-based factors. Specifically, cryptocurrency efficacy (as an aspect of perceived ease of use) helps reduce the level of technostress felt by potential e-retailers in the region. However, the strong positive relationship with cryptocurrency involvement indicates that e-retailers are open to accepting techno-innovations. These findings align with those presented in related studies [23,99].

Moreover, cryptocurrency compatibility (as an aspect of perceived usefulness) appears to be very useful in mapping technostress or involvement. Thus, it is concluded that cryptocurrency compatibility can increase e-retailers' concerns about its uncertainty when the consumers demand it to be embedded into the business environment. Meanwhile, a higher degree of cryptocurrency compatibility e-retailers' businesses also encourages its adoption. As argued by Pietrych et al. [103], cryptocurrency is a market-driven phenomenon. Aside from the TAM-based attributes, the significant role of cryptocurrency's functional transparency in defining technostress among e-retailers highlighted that the technology's fundamental characteristics of digital currencies still trigger ambiguity (including price volatility) [48] and trust-related issues [99] among potential e-retailors. It is critical for this issue to be addressed in the future.

Interestingly, in terms of RQ2, the results highlighted that the behavioral intentions of eretailers constantly shift between techno-uncertainty-imposed technostress and acceptance of cryptocurrencies. Also, the current research underlines that e-retailers' technostress negatively influences their intentions to adopt cryptocurrencies (H4). This result aligns with the stance of Tarafdar et al. [104]. At the same time, e-retailers' positive involvement in cryptocurrencies increases their intentions to adopt cryptocurrencies in their business models (H5), which was also predicted by Tarafdar et al. [104]. However, the current study indicates that the role of techno-uncertainty-based technostress (H4) is slightly more influential than that of techno-involvement (H5). Therefore, cryptocurrencies have not been readily adopted into business models by retailers in the post-COVID-19 era.

RQ3 was addressed by examining the role played by regulatory support in the future of cryptocurrency adoption among e-retailers. This examination revealed that the relationship between techno-involvement and retailers' intentions to adopt cryptocurrencies (H6b) is insignificantly affected by regulatory forces. Meanwhile, regulatory support can reduce technostress (H6a). The strict measures recently taken by China and South Korea, two prominent countries in Asia and the Pacific (discussed in Section 1), might impact the future growth and success of cryptocurrencies in the entire region. There is a need to identify a mechanism that can eliminate illegal transactions and financing for terrorist activities. Different countries should take legislative measures to ensure a secure and trustworthy cryptocurrency market for end users.

\subsection{Implications}

The present research has several theoretical implications. First, the study proposed TAM-based SOR. Although the combination of TAM and SOR has been researched by Ge et al., they studied TAM-based attributes as part of the organism. The present research is unique in that it overlaps SOR and the TAM. Namely, the attributes driving perceived ease of use and perceived usefulness, with the combination of technological attributes, are proposed as stimuli that encourage e-retailers to adopt cryptocurrencies. Moreover, attitudes (one of the core values of the TAM) were further bifurcated into negative and positive aspects by proposing the involvement of techno-uncertainty-based technostress and technology, respectively, as part of the organism. The unique overlap between the TAM and SOR employed in this study generates a detailed understanding of e-retailers' cryptocurrency adoption behavior.

The second major theoretical implication is that technostress contains a broad spectrum of cognitive attributes, as suggested by Ragu-Nathan T.S. Monideepa Tarafdar et al. [82], including techno-invasion, complexity, insecurity, and overload. The current research 
extended this work by highlighting the role of techno-uncertainty-based technostress. Previously, technostress has been considered in the context of education and learning [69], mobile commerce [105], and organizational IS adoption [106]. However, the current research is unique because it addressed the role of technostress in fintech (specifically regarding cryptocurrencies).

Lastly, the recent literature has expressed concern that cryptocurrencies and their mining might negatively affect the environment and other industry stakeholders (i.e., third-party intermediaries and regulatory institutions), as cryptocurrencies could eliminate currently vital entities in the traditional financial industry. The current research is the first to examine the role of regulations in the behavioral mapping of e-retailers' intentions to adopt cryptocurrencies in Asia and the Pacific region.

As far as practical implications are concerned, the findings elucidated that, of all investigated stimuli, cryptocurrency efficacy is the most significant predictor of e-retailers intentions to use cryptocurrencies-consequently, individuals have intrinsic intentions to adopt cryptocurrency. Overall, this factual condition will pose serious challenges to policymakers if institutions decide to help define the future of cryptocurrencies in the region.

Furthermore, the findings show that technostress has a more significant influence than technological involvement on cryptocurrency adoption. Thus, policymakers must explore how to strategically integrate technostress in their policies to reduce the overwhelming role of self-efficacy in e-retailers' tendencies to adopt cryptocurrency. Such policies could also help states to manage and monitor cryptocurrency disseminations. Correspondingly, functional transparency, along with business compatibility and technostress, can be operationalized by policymakers to control cryptocurrency adoption. This could be an effective way to reduce the substantial effect of cryptocurrency efficacy in the particular region of study.

Similarly, matters of functional transparency must be communicated clearly by the institutions that will increase the state's role and effectiveness in managing cryptocurrency and its hiking effect on the market. Accordingly, regulatory support makes no significant contribution to mapping the influence of technology involvement over the intention to accept cryptocurrency. Thus, many e-retailers are adopting cryptocurrency because of its convenience. Still, there is a dire need for functional transparency to advance the institutionalization of cryptocurrencies through regulatory support.

\subsection{Future Studies}

The current research can be further extended by comparing the stances and opinions of e-retailers in Eastern and Western countries. Moreover, the recent strict measures taken by the Australian government [107] might help extend the role of taxation in re-mapping people's intentions to adopt cryptocurrencies in e-retail settings. The present study also highlights the need to measure the readiness of potential cryptocurrency users based on their crypto literacy.

Furthermore, the findings of the present work can be revisited using other existing technology adoption models (e.g., UTAUT or UTAUT2) to explain the stance of e-retailers in different regions. Future studies could describe the opinions and the experiences of e-trailers who have already adopted cryptocurrency into their business environments; such research would indicate how digital currencies in the current market will fare in the future. Qualitative studies could also be conducted to express the challenges that e-retailers might face when contemplating adopting cryptocurrencies.

\section{Conclusions}

Cryptocurrency has recently entered the global market economy, providing a transparent and secure transaction and payment method. However, financial technologies are beginning to threaten formal banking and institutional structures. Motivated by the rise of cryptocurrency that has been observed in the post-COVID-19 era, this paper attempted 
to elucidate how regulatory forces might affect the spread of mechanisms related to cryptocurrencies, as well as e-retailers' intentions to integrate them into their business models.

E-retailers' acceptance of cryptocurrencies has continued to increase and is expected to reach unprecedented heights when barriers to their use are eliminated. This study used PLS-SEM and surveys in Asia and the Pacific region to identify factors that might impact eretailers' intentions to adopt cryptocurrency. The investigation revealed that cryptocurrency efficacy is the strongest driving factor among all considered factors despite potential threats such as price volatility and crypto uncertainty. E-retailers with cryptocurrency efficacy or who perceive digital currencies as highly convenient are more open than others towards using cryptocurrencies.

However, the results also indicate that the strategic use of the perceived functional transparency of cryptocurrency and its related communication by the regulatory institutions and governing bodies can help define how cryptocurrencies will be used in the economic sphere. Thus, they can help control price manipulation and mitigate threats to traditional global financial systems.

Author Contributions: Conceptualization, K.I. and M.A.A.; methodology, F.A.; formal analysis, S.H. and A.N.S.; investigation, R.W. and S.H; writing - original draft preparation, R.W. and S.H.; writing-review and editing, F.A.; supervision, M.A.A. and A.N.S. All authors have read and agreed to the published version of the manuscript.

Funding: This research received no external funding.

Data Availability Statement: Data will be available on reasonable request.

Conflicts of Interest: The manuscript holds no conflict of interest among all contributing authors.

\section{References}

1. Leong, K. FinTech (Financial Technology): What is It and How to Use Technologies to Create Business Value in Fintech Way? Int. J. Innov. Manag. Technol. 2018, 9, 74-78. [CrossRef]

2. Park, J.; Park, S.; Kim, K.; Lee, D. CORUS: Blockchain-based trustworthy evaluation system for efficacy of healthcare remedies. In Proceedings of the 2018 IEEE International Conference on Cloud Computing Technology and Science (CloudCom), Nicosia, Cyprus, 10-13 December 2018; pp. 181-184.

3. Rupeika-Apoga, R.; Thalassinos, E.I. Ideas for a regulatory definition of FinTech. Int. J. Econ. Bus. Adm. 2020, 8, 136-154. [CrossRef]

4. Yao, M.; Di, H.; Zheng, X.; Xu, X. Impact of payment technology innovations on the traditional financial industry: A focus on China. Technol. Forecast. Soc. Chang. 2018, 135, 199-207. [CrossRef]

5. Coffie, C.P.K.; Hongjiang, Z.; Mensah, I.A.; Kiconco, R.; Simon, A.E.O. Determinants of FinTech payment services diffusion by SMEs in Sub-Saharan Africa: Evidence from Ghana. Inf. Technol. Dev. 2020, 27, 539-560. [CrossRef]

6. Solarz, M.; Swacha-Lech, M. Determinants of the adoption of innovative fintech services by millennials. E + M Ekon. Manag. 2021, 24, 149-166. [CrossRef]

7. Polasik, M.; Piotrowska, A.I.; Wisniewski, T.P.; Kotkowski, R.; Lightfoot, G. Price Fluctuations and the Use of Bitcoin: An Empirical Inquiry. Int. J. Electron. Commer. 2015, 20, 9-49. [CrossRef]

8. Kijkasiwat, P. Opportunities and Challenges for Fintech Startups: The Case Study of Thailand. ABAC J. 2021, 41, 41-60.

9. Vasenska, I.; Dimitrov, P.; Koyundzhiyska-Davidkova, B.; Krastev, V.; Durana, P.; Poulaki, I. Financial Transactions Using FINTECH during the COVID-19 Crisis in Bulgaria. Risks 2021, 9, 48. [CrossRef]

10. Jiang, S.; Li, Y.; Lu, Q.; Hong, Y.; Guan, D.; Xiong, Y.; Wang, S. Policy assessments for the carbon emission flows and sustainability of Bitcoin blockchain operation in China. Nat. Commun. 2021, 12, 1-10. [CrossRef]

11. Qin, M.; Su, C.-W.; Tao, R. BitCoin: A new basket for eggs? Econ. Model. 2020, 94, 896-907. [CrossRef]

12. Papantoniou, C. Esri Which Countries Use Cryptocurrency Most? 2021, p. 1. Available online: https://www.esri.com/about/ newsroom/publications/wherenext/cryptocurrency-use-by-geography/ (accessed on 1 May 2021).

13. Mariana, S. Cryptocurrency-definition, functions, advantages and risks. Підприємництво і торгівля 2021, 30, 5-10.

14. Molling, G.; Klein, A.; Hoppen, N.; Dalla, R.R. Cryptocurrency: A Mine of Controversies. J. Inf. Syst. Technol. Manag. 2020, 17, 1-15. [CrossRef]

15. Zook, M.A.; Blankenship, J. New spaces of disruption? The failures of Bitcoin and the rhetorical power of algorithmic governance. Geoforum 2018, 96, 248-255. [CrossRef]

16. De Haro-Olmo, F.J.; Varela-Vaca, Á.J.; Álvarez-Bermejo, J.A. Blockchain from the perspective of privacy and anonymisation: A systematic literature review. Sensors 2020, 20, 7171. [CrossRef] 
17. Albayatia, H.; Kim, S.K.; Rho, J.J. Accepting financial transactions using blockchain technology and cryptocurrency: A customer perspective approach. Technol. Soc. 2020, 62, 101320. [CrossRef]

18. Wani, T.A.; Ali, S.W. Innovation Diffusion Theory Review \& Scope in the Study of Adoption of Smartphones in India. J. Gen. Manag. Res. 2015, 3, 101-118.

19. Cheema, M.A.; Faff, R.W.; Szulczuk, K. The 2008 Global Financial Crisis and COVID-19 Pandemic: How Safe are the Safe Haven Assets? COVID Econ. Vetted Real-Time Pap. 2020, 1, 88-115. [CrossRef]

20. Wunsche, A. Technological Disruption of Capital Markets and Reporting? An Introduction to Blockchain; CPA Chartered Professional Accountants Canada: Toronto, ON, Canada, 2016; pp. 1-27.

21. Arias-Oliva, M.; Pelegrín-Borondo, J.; Matías-Clavero, G. Variables Influencing Cryptocurrency Use: A Technology Acceptance Model in Spain. Front. Psychol. 2019, 10, 475. [CrossRef] [PubMed]

22. Johng, H.; Kim, D.; Hill, T.; Chung, L. Using blockchain to enhance the trustworthiness of business processes: A goal-oriented approach. In Proceedings of the 2018 IEEE International Conference on Services Computing (SCC), San Francisco, CA, USA, 2-7 July 2018; pp. 249-252. [CrossRef]

23. Hove, L.; Van Karimov, F.P. The role of risk in e-retailers' adoption of payment methods: Evidence for transition economies. Electron. Commer. Res. 2016, 16, 27-72. [CrossRef]

24. Grüschow, R.M.; Kemper, J.; Brettel, M. How do different payment methods deliver cost and credit efficiency in electronic commerce? Electron. Commer. Res. Appl. 2016, 18, 27-36. [CrossRef]

25. Hung, J.-C.; Liu, H.-C.; Yang, J.J. Trading activity and price discovery in Bitcoin futures markets. J. Empir. Finance 2021, 62, 107-120. [CrossRef]

26. Rogers, E.M. Diffusion of Innovation, 4th ed.; The Free Press: New York, NY, USA, 1995.

27. Fishbein, M.; Ajzen, I. Belief, Attitude, Intention, and Behavior: An Introduction to Theory and Research; Addison-Wesley Pub: Boston, MA, USA, 1975; ISBN 9780201020892.

28. Rodd, M.G.; Miskin, A.; Tomlinson, J. Knowledge management in a multimedia environment: Some key research issues. In Proceedings of the 2002 Student Conference on Research and Development, Shah Alam, Malaysia, 17 July 2002; pp. 1-7. [CrossRef]

29. Venkatesh, V.; Morris, M.G.; Davis, G.B.; Davis, F.D.; Hall, M.; Davis, G.B.; Davis, F.D.; Walton, S.M. User a cceptance of information technology: Toward a unified view. MIS Q. 2003, 27, 425-478. [CrossRef]

30. Venkatesh, V.; Thong, J.Y.L.; Xu, X. Consumer Acceptance and Use of Information Technology: Extending the Unified Theory. MIS Q. 2012, 36, 157-178. [CrossRef]

31. Zhai, X.; Dong, Y.; Wang, S.; Wang, L.; Yuan, J. Exploring eye-tracking analyses of EFL learners' cognitive processing of reduced relative clause. Clust. Comput. 2019, 22, 14181-14192. [CrossRef]

32. Zhai, X.; Fang, Q.; Dong, Y.; Wei, Z.; Yuan, J.; Cacciolatti, L.; Yang, Y. The effects of biofeedback-based stimulated recall on self-regulated online learning: A gender and cognitive taxonomy perspective. J. Comput. Assist. Learn. 2018, 34, 775-786. [CrossRef]

33. Kim, M. A Psychological Approach to Bitcoin Usage Behavior in the Era of COVID-19: Focusing on the Role of Attitudes toward Money. J. Retail. Consum. Serv. 2021, 62, 102606. [CrossRef]

34. Gazali, H.M.; Ismail, C.M.H.B.C.; Amboala, T. Exploring the intention to invest in cryptocurrency: The case of bitcoin. In Proceedings of the 2018 International Conference on Information and Communication Technology for the Muslim World (ICT4M), Kuala Lumpur, Malaysia, 23-25 July 2018; pp. 64-68.

35. Nadeem, M.A.; Liu, Z.; Pitafi, A.H.; Younis, A.; Xu, Y. Investigating the Adoption Factors of Cryptocurrencies-A Case of Bitcoin: Empirical Evidence From China. SAGE Open 2021, 11, 2158244021998704. [CrossRef]

36. Mehrabian, A.; Russell, J.A. An Approach to Environmental Psychology; M.I.T. Press: Cambridge, MA, USA, $1974 ;$ pp. $62-65$.

37. Song, S.; Yao, X.; Wen, N. What motivates Chinese consumers to avoid information about the COVID-19 pandemic?: The perspective of the stimulus-organism-response model. Inf. Process. Manag. 2021, 58, 102407. [CrossRef]

38. Peng, C.; Kim, Y.G. Application of the Stimuli-Organism-Response (S-O-R) Framework to Online Shopping Behavior. J. Internet Commer. 2014, 13, 159-176. [CrossRef]

39. Jacoby, J. Stimulus-organism-response reconsidered: An evolutionary step in modeling (consumer) behavior. J. Consum. Psychol. 2002, 12, 51-57. [CrossRef]

40. Vieira, V.A. Stimuli-organism-response framework: A meta-analytic review in the store environment. J. Bus. Res. 2013, 66, 1420-1426. [CrossRef]

41. Flavián, C.; Ibáñez-Sánchez, S.; Orús, C. Integrating virtual reality devices into the body: Effects of technological embodiment on customer engagement and behavioral intentions toward the destination. J. Travel Tour. Mark. 2019, 36, 847-863. [CrossRef]

42. Ye, Q.; Anwar, M.A.; Zhou, R.; Asmi, F. Short stay, long impact: Ecological footprints of sojourners. Environ. Sci. Pollut. Res. 2020, 17, 11797-11808. [CrossRef] [PubMed]

43. Guo, J.; Liu, Z.; Liu, Y. Key success factors for the launch of government social media platform: Identifying the formation mechanism of continuance intention. Comput. Hum. Behav. 2016, 55, 750-763. [CrossRef]

44. Kim, M.J.; Lee, C.; Jung, T. Exploring Consumer Behavior in Virtual Reality Tourism Using an Extended Stimulus-OrganismResponse Model. J. Travel Res. 2018, 59, 69-89. [CrossRef]

45. Pandita, S.; Mishra, H.G.; Chib, S. Psychological impact of COVID-19 crises on students through the lens of Stimulus-OrganismResponse (SOR) model. Child. Youth Serv. Rev. 2021, 120, 105783. [CrossRef] [PubMed] 
46. Gatautis, R.; Vitkauskaite, E.; Gadeikiene, A.; Piligrimiene, Z. Gamification as a Mean of Driving Online Consumer Behaviour: SOR Model Perspective. Inz. Ekon. Econ. 2016, 27, 90-97. [CrossRef]

47. Bagozzi, R.P. The Legacy of the Technology Acceptance Model and a Proposal for a Paradigm Shift. J. Assoc. Inf. Syst. 2007, 8 , 244-254. [CrossRef]

48. Delfabbro, P.; King, D.L.; Williams, J. The psychology of cryptocurrency trading: Risk and protective factors. J. Behav. Addict. 2021, 10, 201-207. [CrossRef] [PubMed]

49. Berger, J.L.; Girardet, C.; Vaudroz, C.; Crahay, M. Teaching Experience, Teachers' Beliefs, and Self-Reported Classroom Management Practices: A Coherent Network. SAGE Open 2018, 8, 2158244017754119. [CrossRef]

50. Ullah, N.; Al-Rahmi, W.M.; Alzahrani, A.I.; Alfarraj, O.; Alblehai, F.M. Blockchain technology adoption in smart learning environments. Sustainability 2021, 13, 1801. [CrossRef]

51. Plouffe, C.R.; Hulland, J.S.; Vandenbosch, M. Research Report: Richness Versus Parsimony in Modeling Technology Adoption Decisions-Understanding Merchant Adoption of a Smart Card-Based Payment System. Inf. Syst. Res. 2001, 12, 208-222. [CrossRef]

52. Ayedh, A.; Echchabi, A.; Battour, M.; Omar, M. Malaysian Muslim investors' behaviour towards the blockchain-based Bitcoin cryptocurrency market. J. Islam. Mark. 2020, 12, 690-704. [CrossRef]

53. Sun, Y.; Bhattacherjee, A.; Ma, Q. Extending technology usage to work settings: The role of perceived work compatibility in ERP implementation. Inf. Manag. 2009, 46, 351-356. [CrossRef]

54. Sander, F.; Semeijn, J.; Mahr, D.; Mahr, D. The acceptance of blockchain technology in meat traceability and transparency. Br. Food J. 2018, 120, 2066-2079. [CrossRef]

55. Calvão, F.; Archer, M. Digital extraction: Blockchain traceability in mineral supply chains. Polit. Geogr. 2021, 87, 102381. [CrossRef]

56. Lin, J.; Shen, Z.; Miao, C. Using blockchain technology to build trust in sharing LoRaWAN IoT. In Proceedings of the 2nd International Conference on Crowd Science and Engineering, Beijing, China, 6-9 July 2017; pp. 38-43.

57. Pardo, M.Á.; Jiménez, E.; Pérez-Villarreal, B. Misdescription incidents in seafood sector. Food Control. 2016, 62, 277-283. [CrossRef]

58. Ross, O.; Jensen, J.; Asheim, T. Assets under Tokenization. SSRN Electron. J. 2019, 1-9. [CrossRef]

59. Grover, P.; Kar, A.K.; Janssen, M.; Ilavarasan, P.V. Perceived usefulness, ease of use and user acceptance of blockchain technology for digital transactions-insights from user-generated content on Twitter. Enterp. Inf. Syst. 2019, 13, 771-800. [CrossRef]

60. Chiappetta, M. The Technostress: Definition, symptoms and risk prevention. Senses Sci. 2017, 4, 358-361. [CrossRef]

61. John, S.P. The integration of information technology in higher education: A study of faculty's attitude towards IT adoption in the teaching process. Contaduria y Adm. 2015, 60, 230-252. [CrossRef]

62. Tarafdar, M.; Tu, Q.; Ragu-Nathan, T. Impact of technostress on end-user satisfaction and performance. J. Manag. Inf. Syst. 2010, 27, 303-334. [CrossRef]

63. Beames, J.R.; Johnston, L.; O’Dea, B.; Torok, M.; Christensen, H.; Boydell, K.M.; Werner-Seidler, A. Factors that help and hinder the implementation of digital depression prevention programs: School-based cross-sectional study. J. Med. Internet Res. 2021, 23, e26223. [CrossRef] [PubMed]

64. Tams, S.; Thatcher, J.B.; Grover, V. Concentration, competence, confidence, and capture: An experimental study of age, interruption-based technostress, and task performance. J. Assoc. Inf. Syst. 2018, 19, 857-908. [CrossRef]

65. Chou, H.L.; Chou, C. A multigroup analysis of factors underlying teachers' technostress and their continuance intention toward online teaching. Comput. Educ. 2021, 175, 104335. [CrossRef]

66. Salazar-Concha, C.; Ficapal-Cusí, P.; Boada-Grau, J.; Camacho, L.J. Analyzing the evolution of technostress: A science mapping approach. Heliyon 2021, 7, e06726. [CrossRef] [PubMed]

67. Stadin, M.; Nordin, M.; Broström, A.; Magnusson Hanson, L.L.; Westerlund, H.; Fransson, E.I. Technostress operationalised as information and communication technology (ICT) demands among managers and other occupational groups-Results from the Swedish Longitudinal Occupational Survey of Health (SLOSH). Comput. Human Behav. 2021, 114, 106486. [CrossRef]

68. Fuglseth, A.M.; Sørebø, Ø. The effects of technostress within the context of employee use of ICT. Comput. Human Behav. 2014, 40, 161-170. [CrossRef]

69. Li, L.; Wang, X. Technostress inhibitors and creators and their impacts on university teachers' work performance in higher education. Cogn. Technol. Work 2021, 23, 315-330. [CrossRef]

70. Atabek, O. Associations between Emotional States, Self-Efficacy For and Attitude Towards Using Educational Technology. Int. J. Progress. Educ. 2020, 16, 175-194. [CrossRef]

71. Tarafdar, M.; Tu, Q.; Ragu-Nathan, B.S.; Ragu-Nathan, T.S. The impact of technostress on role stress and productivity. J. Manag. Inf. Syst. 2007, 24, 301-328. [CrossRef]

72. Rogers, T.; Kowal, J. Selection of glass, anodic bonding conditions and material compatibility for silicon-glass capacitive sensors Sens. Actuators A Phys. 1995, 46, 113-120. [CrossRef]

73. Altawallbeh, M.; Soon, F.; Thiam, W.; Alshourah, S. Mediating role of attitude, subjective norm and perceived behavioural control in the relationships between their respective salient beliefs and behavioural intention to adopt e-learning among instructors in Jordanian universities. J. Educ. Pract. 2015, 6, 152-160.

74. Ko, T.; Lee, J.; Ryu, D. Blockchain Technology and Manufacturing Industry: Real-Time Transparency and Cost Savings. Sustainability 2018, 10, 4274. [CrossRef] 
75. Tezel, A.; Papadonikolaki, E.; Yitmen, I.; Hilletofth, P. Preparing construction supply chains for blockchain technology: An investigation of its potential and future directions. Front. Eng. Manag. 2020, 7, 547-563. [CrossRef]

76. DuPree, Y. Determinants of Intention to Use New Technology: An Investigation of Students in Higher Education. Ph.D. Thesis, Nova Southeastern University, Fort Lauderale, FL, USA, 2015.

77. Makarov, I.; Schoar, A. Trading and arbitrage in cryptocurrency markets. J. Financ. Econ. 2020, 135, 293-319. [CrossRef]

78. Chakravaram, V.; Ratnakaram, S.; Agasha, E. Cryptocurrency: Threat or Opportunity; Springer: Singapore, 2020; ISBN 9789811579615.

79. Bolotaeva, O.S.; Stepanova, A.A.; Alekseeva, S.S. The Legal Nature of Cryptocurrency. In IOP Conference Series: Earth and Environmental Science; IOP Publishing: Bristol, UK, 2019; Volume 272, p. 032166. [CrossRef]

80. Nolasco Braaten, C.; Vaughn, M.S. Convenience Theory of Cryptocurrency Crime: A Content Analysis of U.S. Federal Court Decisions. Deviant Behav. 2021, 42, 958-978. [CrossRef]

81. Daniel, W.W.; Cross, C.L. Biostatistics: A Foundation for Analysis in the Health Sciences, 11th ed.; John Wiley \& Sons Inc.: New York, NY, USA, 2018.

82. Ragu-Nathan, T.S.; Monideepa, T.; Ragu-Nathan, B.S.; Tu, Q. The Consequences of Technostress for End Users in Organizations: Conceptual Development and Empirical Validation. Inf. Syst. Res. 2008, 19, 417-433. [CrossRef]

83. Zhu, Y.; Kanjanamekanant, K. No trespassing: Exploring privacy boundaries in personalized advertisement and its effects on ad attitude and purchase intentions on social media. Inf. Manag. 2021, 58, 103314. [CrossRef]

84. Fazal-e-hasan, S.M.; Amrollahi, A.; Mortimer, G.; Adapa, S. Computers in Human Behavior A multi-method approach to examining consumer intentions to use smart retail technology. Comput. Hum. Behav. 2021, 117, 106622. [CrossRef]

85. Urban, B.; Kujinga, L. The institutional environment and social entrepreneurship intentions. Int. J. Entrep. Behav. Res. 2017, 23, 638-655. [CrossRef]

86. Venkatesh, V.; Thong, J.Y.; Chan, F.K.; Hu, P.J. Managing Citizens Uncertainty in E-Government Services: The Mediating and Moderating Roles of Transparency and Trust. Inf. Syst. Res. 2016, 27, 87-111. [CrossRef]

87. Dutta, D.K.; Gwebu, K.L.; Wang, J. Personal innovativeness in technology, related knowledge and experience, and entrepreneurial intentions in emerging technology industries: A process of causation or effectuation? Int. Entrep. Manag. J. 2015, 11, 529-555. [CrossRef]

88. Hair, J.F.; Black, W.C.; Babin, B.J.; Anderson, R.E. Multivariate Data Analysis, 7th ed.; Pearson Education: Upper Saddle River, NJ, USA, 2014

89. Harman, H.H. Modern Factor Analysis; University of Chicago Press: Chicago, IL, USA, 1976; ISBN 0226316521.

90. Elliot, A.C.; Woodward, W.A. IBM SPSS by Example: A Practical Guide to Statistical Data Analysis, 2nd ed.; SAGE Publication: London, UK, 2016.

91. Hu, L.T.; Bentler, P.M. Cutoff criteria for fit indexes in covariance structure analysis: Conventional criteria versus new alternatives. Struct. Equ. Model. 1999, 6, 1-55. [CrossRef]

92. Hooper, D.; Mullen, J.; Hooper, D.; Coughlan, J.; Mullen, M.R. Structural Equation Modelling: Guidelines for Determining Model Fit. Electron. J. Bus. Res. Methods 2008, 6, 53-60.

93. Keren, F.; Siddiquei, A.N.; Anwar, M.A.; Asmi, F.; Ye, Q. What Explains Natives and Sojourners Preventive Health Behavior in a Pandemic: Role of Media and Scientific Self-Efficacy. Front. Psychol. 2021, 12, 2446. [CrossRef]

94. Zhai, X.; Asmi, F.; Zhou, R.; Ahmad, I.; Anwar, M.A.; Saneinia, S.; Li, M. Investigating the Mediation and Moderation Effect of Students Addiction to Virtual Reality Games: A Perspective of Structural Equation Modeling. Discret. Dyn. Nat. Soc. 2020. [CrossRef]

95. Pallant, J. SPSS Survival Manual: A Step by Step Guide to Data Analysis Using IBM SPSS, 6th ed.; McGraw-Hill Education: Berkshire, UK, 2016; ISBN 9780335261543.

96. Antonius, R. Interpreting Quantitative Data with SPSS, 1st ed.; SAGE Publications: London, UK, 2003.

97. Fornell, C.; Larcker, D. Evaluating Structural Equation Models with Unobservable Variables and Measurement Error. J. Mark. Res. 1981, 18, 39-50. [CrossRef]

98. Henseler, J. ADANCO 2.0.1: User Manual; Composite Modeling GmbH \& Co. KG: Kleve, Germany, 2017.

99. Jonker, N. What drives the adoption of crypto-payments by online retailers? Electron. Commer. Res. Appl. 2019, 35, 100848. [CrossRef]

100. Asmi, F.; Anwar, M.A.; Zhou, R.; Nawaz, M.A.; Tahir, F. Predicting functional transparency and privacy concerns as future challenge for diffusion of IoT and blockchain. In Proceedings of the 3rd International Conference on Big Data and Internet of Things, Melbourn, Australia, 22-24 August 2019; pp. 99-104. [CrossRef]

101. Turja, T.; Aaltonen, I.; Taipale, S.; Oksanen, A. Information \& Management Robot acceptance model for care (RAM-care): A principled approach to the intention to use care robots. Inf. Manag. 2020, 57, 103220. [CrossRef]

102. Brooks, S.; Califf, C. Social media-induced technostress: Its impact on the job performance of it professionals and the moderating role of job characteristics. Comput. Net. 2017, 114, 143-153. [CrossRef]

103. Pietrych, L.; Sandubete, J.E.; Escot, L. Solving the chaos model-data paradox in the cryptocurrency market. Commun. Nonlinear Sci. Numer. Simul. 2021, 102, 105901. [CrossRef]

104. Tarafdar, M.; Pullins, E.B.; Ragu-Nathan, T.S. Technostress: Negative effect on performance and possible mitigations. Inf. Syst. J. 2015, 25, 103-132. [CrossRef] 
105. Lee, S.J.; Jin, S.H.; Choi, B.J. The influence of technostress and antismart on continuous use of smartphones. Lect. Notes Eng. Comput. Sci. 2012, 1, 303-308.

106. Boyer-Davis, S. Technostress: An antecedent of job turnover intention in the accounting profession. J. Bus. Account. 2019, 12, 49-63.

107. Arthur, M. The uncertainty of cryptocurrency regulation: Achieving effective regulation without stifling law enforcement and innovation. Ethos Off. Publ. Law Soc. Aust. Cap. Territ. 2021, 1, 26-30. 